\title{
Pengaruh Nilai Virtual Item Terhadap Intensi Pembelian Virtual Item dalam Game Online PUBG Mobile
}

\author{
Muhammad Hafni Herawan \\ Universitas Lambung Mangkurat \\ M. Yudy Rachman \\ Universitas Lambung Mangkurat \\ Email :yrachman@ulm.ac.id
}

\begin{abstract}
Abstrak
Penelitian dilakukan dengan tujuan untuk menggambarkan intensi pembelian virtual item para pemain game online yaitu PUBG Mobile, yang dipengaruhi oleh nilai virtual item pada game tersebut. Metode yang digunakan yaitu metode kuantitatif, dengan menyertakan masyarakat Banjarmasin yang merupakan pemain game online PUBG sebagai populasi penelitian. Dari populasi penelitian ini kemudian ditarik 100 sampel sebagai responden penelitian. Teknik sampling yang digunakan dalam menarik sampel yaitu Judgmental sampling. Sedangkan untuk menganalisis data pada penelitian ini maka digunakan regresi linier berganda. Berdasarkan temuan penelitian ini maka didapat hasil sebagai berikut : Hasil penelitian menunjukkan bahwasannya intensi pembelian virtual item dari para pemain game online PUBG Mobile dipengaruhi oleh nilai fungsional dari virtual item, namun dari hasil penelitian ini pula didapat bukti bahwa nilai social dan juga nilai fungsional ternyata belum memiliki andil terhadap intensi pembelian virtual item para pemain game online PUBG. Semakin meningkatnya nilai dari sebuah virtual item akan membuat semakin meningkat pula intensi para pemain untuk membeli virtual item dalam permainan tersebut, dan hal ini berarti menunjukan nilai dari virtual item akan mempengaruhi intensi untuk membeli virtual item permainan tersebut.
\end{abstract}

Kata Kunci: nilai virtual item, nilai fungsional, nilai sosial, nilai emosional, intensi pembelian

\section{Pendahuluan}

Teknologi komunikasi dewasa ini telah berkembang pesat dan kedepannya akan terus berkembang, tujuan perkembangan ini tentunya tidak lepas dari adanya manfaat positif yang didapatkan pada berbagai aspek, memberikan alternative serta kemudahan dalam melakukan berbagai macam hal, bahkan juga dapat menemukan cara yang belum pernah dilakukan sebelumnya dalam menyelesaikan sebuah kegiatan. Teknologi komunikasi yang dimaksud didalamnya terutama internet yang lebih banyak digunakan untuk keperluan berkomunikasi, transaksi bisnis, interaksi sosial, hingga sampai pada sektor hiburan. Di bidang hiburan seperti game, seiring dengan perkembangan internet tersebut yang pada awalnya game pada komputer hanyalah bersifat offline dan tidak dapat mempertemukan pemain lain diberbagai tempat berbeda kemudian game yang bersifat offline berkembang menjadi online. Game online disini merupakan sebuah game yang dapat dimainkan para pemain atau dengan kata lain yaitu pengguna, yang berada di berbagai tempat berbeda, dan melalui game ini pula para pemain/ pengguna dapat saling sharing informasi dan sharing ruang jaringan melalui koneksi internet yang sama. Tidak sampai disini beberapa game online yang dulunya hanya ada pada perangkat 


\section{Muhammad Hafni Herawan, M. Yudy Rachman}

komputer kini bisa dimainkan dengan smartphone sehingga pemain pun dapat bermain dimana pun dan kapan pun dia mau.

Salah satu game populer dengan model permainan free-to-play tidak lain adalah PUBG Mobile. Game online PUBG Mobile ini merupakan sebuah game "MMOFPS" yang bersetting peperangan dengan masing masing player menyandang item item virtual yang serupa dengan senjata-senjata militer. Game ini dirilis pada tanggal 9 Februari 2018 dan menjadi peringkat pertama sebagai game paling populer di tahun 2020. PUBG Mobile sendiri sebenarnya merupakan fenomena yang memukau dunia entertainment games interaktif yang diadaptasikan dari PlayerUnknown's Battlegrounds (PUBG), yang juga merupakan game Battle Royale Original di Xbox One, personal computer PC, dan bahkan menempati peringkat pertama dengan pemain terbanyak di 2017 lalu pada game steam.

Dalam Tunjungsari \& Lunardy (2016) pendapatan publisher bersumber dari:

1) Game berbayar, pemain membayar sejumlah uang tertentu setiap bulannya agar bisa memainkan game tersebut.

2) Membeli game, pemain membayar pada saat menginstall game dan registrasi akun pengguna tanpa membayar biaya per-bulannya lagi.

3) Game gratis, pemain dapat memainkan game tersebut tanpa membayar biaya apapun.

Menurut sumber pendapatan game online ini, pendapatan developer game atau dikenal pula dengan penerbit (publisher) salah satunya berasal dari penjualan item virtual, dan yang lainnya dapat berasal dari iklan, real estat atau penggunaan lahan, souvenir dan merchandise, bahkan juga transaksi antar pemain, biaya langganan, lelang hingga acara atau turnamen game, paket ekspansi, TrialPay, dan masih banyak lagi.

Tunjungsari \& Lunardy (2016) meyakini bahwa kebanyakan game online di Indonesia menggunakan model game gratis atau disebut free to play. Bahkan pendapatan dari developer game online yang terbesar salah satunya yakni berasal dari penjualan item virtual dengan istilah lain yaitu pendapatan yang biasa dikenal dengan "microtransactions". Hamari \& Lehdonvirta (2010) menjelaskan bahwa penjualan produk virtual yang dimana uang sungguhan yang dikeluarkan pemain game menjadi sebuah produk virual sehingga menjadi sumber pendapatan bagi penerbit game tersebut. Di Indonesia, terdapat dua metode pertukaran uang asli dengan produk virtual yang populer, yaitu melalui payment gateway (seperti Gudangvoucher, Indomog, Unipin), voucher fisik (agen, warung internet, tenaga penjual) Tunjungsari dan Lunardy (2016).

Bahkan sekarang, game online bukan hanya sekedar untuk bermain saja, virtual item yang disediakan dalam game online menjadi sumber pendapatan bagi publisher game online dengan adanya virtual ekonomi menjadikan pemain game online dapat bertransaksi jual beli produk virtual di dalam game menggunakan uang asli/nyata. Ho A. (2014) memaparkan bahwa dalam industry video game sekarang ini, ekonomi virtual memang adalah sebuah model bisnis yang ada. Item atau barang virtual tidak hanya memberikan manfaat dalam sebuah game, tetapi juga mendatangkan manfaat dan potensi yang menjanjikan bagi sebuah developer atau penerbit game. Kesuksesan ekonomi virtual telah memicu kontroversi terutama mengenai permasalahan dimana barang virtual ternyata terbutki memiliki nilai komersial secara riil, meski dalam sebuah lingkup game online. Lehdonvirta (2009) memaparkan bahwa virtual item yang dimaksud pada penelitian ini mencakup tiga kualitas. Tiga kualitas yang dimaksud terdiri dari kualitas fungsional, kemudian kualitas emosional, dan juga kualitas sosial. Kinerja dan fungsionalitas virtual item terkait sebuah game akan menunjukan kualitas fungsionalnya. sedangkan penampilan, sumber, kemampuan penyesuaian dan kelangkaan dari virtual item merupakan perwujudan dari kualitas emosional dan kualitas sosialnya. Menurut Monroe (1990) dalam (Tunjungsari \& Lunardy, 2016) terdapat 2 faktor pembentuk nilai fungsional suatu produk, yaitu: kualitas dan price utility. Dilanjutkan Thaler (1985) dalam (Tunjungsari 
\& Lunardy, 2016) dalam bertransaksi pembelian untuk produk virtual, utilitas harga yang lebih besar akan menciptakan utilitas akuisisi dan kemauan yang lebih besar pula untuk membeli, dikarenakan konsumen percaya bahwa transaksi yang dilakukan tersebut lebih bernilai.

Tunjungsari \& Lunardy (2016) memaparkan bahwa seorang individu dapat mengekspresikan citra dari dirinya secara social terhadap pemain lain dengan cara membeli dan menggunakan sebuah produk. Nilai sosial virtual item menurut Solomon (2011) dalam (Tunjungsari \& Lunardy, 2016) Produk yang digunakan untuk kepentingan sosial memiliki arti sebagai sebuah simbol.

Kim et al. (2009) dalam (Tunjungsari \& Lunardy, 2016) memiliki pendapat bahwa kesenangan atau biasa diungkapkan dengan playfulness dan juga estetika dapat menghadirkan nilai emosional pada sebuah produk virtual. Dari sudut pandang pembeli, kesenangan (playfulness) yang diperoleh dengan memiliki item produk virtual ternyata dapat memunculkan intensi pembeli tersebut dalam membeli sebuah produk, Kim et al. (2009) dalam (Tunjungsari \& Lunardy, 2016). Penelitian ini memilih untuk meneliti PUBG Mobile karena peneliti tertarik untuk meneliti tentang pembelian produk virtual dalam game online menggunakan uang sungguhan. Peneliti juga ingin mengetahui apa yang membuat mereka rela membeli virtual item dan mengorbankan uang asli/nyata dengan teori nilai virtual untuk menjelaskan fenomena ini. Penelitian kali ini dilaksanakan dengan beberapa tujuan antara lain : (1) Memberikan analisis mengenai pengaruh dari nilai fungsional virtual item terhadap munculnya intensi untuk membeli virtual item pada game online PUBG Mobile (2) Memberikan analisis mengenai pengaruh nilai sosial virtual item terhadap intensi untuk membeli virtual item pada game online PUBG Mobile (3) Memberikan analisis mengenai pengaruh nilai emosional virtual item terhadap intensi untuk membeli virtual item dalam pada online PUBG Mobile.

\section{Landasan Teori dan Pengembangan Hipotesis}

\section{Intensi Pembelian}

Menurut Fishbein \& Ajzen (1975) dalam (Tunjungsari \& Lunardy, 2016) intensi pembelian diartikan sebagai kesediaan individu untuk membeli produk atau jasa tertentu. American Marketing Association dalam (Tunjungsari \& Lunardy, 2016) mengartikan intensi pembelian sebagai " a decision plan to buy a particular product or brand created through a choice/decision process".

Teori Planned Behavior adalah teori yang telah dikembangkan oleh Ajzen. Teori ini ialah kesempurnaan yang berasal teori "Reason action" yang dicetuskan oleh Fishbein dan Ajzen. Fokus utama dalam teori ini, yaitu niat individu untuk bertindak melakukan suatu hal tertentu. Niat juga bisa dilihat pada faktor motivasi yang mempengaruhi sebuah perilaku, maksudnya adalah menunjukkan sekuat apa orang tersebut berusaha untuk mencoba hal tertentu, dan upaya seperti apa yang akan dilakukan orang tersebut untuk mengambil tindakan tertentu, Fishbein \& Ajzen (1975) dalam (Suryono \& Subriadi, 2016).

Teori Reason Action mengatakan niat memiliki dua determinan, yaitu sikap pribadi dan norma subjektif. Sikap adalah evaluasi positif atau negatif seseorang terhadap suatu perilaku tertentu. Sedangkan norma subjektif yaitu persepsi seseorang tentang tekanan sosial dalam melakukan tindakan atau tidak melakukan perilaku tertentu. Namun, Ajzen percaya dengan teori "Reason Action" masih belum dapat menjelaskan perilaku yang tidak sepenuhnya dikendalikan oleh manusia. Oleh karena itu, pada teori perilaku terencana, Ajzen menambah satu faktor yang menjadi salah satu penentu intensi, yaitu persepsi pengendalian perilaku, yaitu persepsi seseorang atas penguasaannya atas perilaku tertentu., Fishbein \& Ajzen (1975) dalam (Suryono \& Subriadi, 2016). 


\section{Nilai Virtual Item}

Guo dan Barnes (2012) dalam (Tunjungsari \& Lunardy, 2016) memaparkan bahwa item virtual dalam hal ini produk virtual meruapakan sebuah produk yang bersifat non fisik dibuat dan dipergunakan dalam cakupan dunia virtual/maya, dengan tujuan meningkatkan pengalaman para pemainnya. Penelitian lain yang dilakukan Cha (2011) memberikan definisi tentang itemvirtual atau produk virtual yaitu sebuah produk atau jasa, dimana pembelian dan penggunaannya terbatas pada cakupan ruang online tertentu. Dapat disimpulkan bahwa pengertian nilai yang berkaitan dengan item game online adalah, harga atau makna juga kualitas isi suatu item dalam kegunaannya dalam game online yang bersangkutan yang memengaruhi layak tidaknya item tersebut digunakan.

Penjualan item yang bersifat virtual ini telah menjadi pendapatan utama bagi developer atau pemasok game online dari sekian alternative untuk menghasilkan pendapatan. Lehdonvirta (2009) menunjukkan bahwa virtual item memiliki 3 kualitas, yaitu kualitas fungsional, emosional, dan sosial

Dimensi nilai menurut Ho \& Wu (2012), adalah sebagai berikut:

1). Nilai dari fungsionalnya

a. Kompetensi karakter, karakter game online yang menggunakan virtual item yang disediakan oleh game dapat menambah kemampuan pemainnya dalam mendapatkan skor lebih banyak dan menaikkan levelnya lebih cepat serta dapat membantu memenangkan game tersebut.

b. Utilitas harga, menunjukkan kelayakan suatu nilai apakah virtual item tersebut memiliki harga yang masuk akal dan sepadan jika dibeli serta virtual item tersebut dianggap bagus sesuai dengan harganya karena dapat merubah visualisasi karakter nya menjadi lebih baik.

c. Kualitas fungsi, mengarah pada standar kualitas dari virtual item yang diterima oleh pemain dan dapat membuat pemain unggul dalam bermain.

2). Nilai dari sosialnya

a. Ekspresi citra diri sosial, lebih cenderung kepada perhatian pemain lain pada saat menggunakan virtual item dan diakui bahwa virtual item yang digunakan memang terlihat menarik dan berkesan pada pemain lain serta juga dapat memberikan kesan yang baik kepada pemain lain.

b. Dukungan hubungan sosial, terciptanya hubungan antar pemain seperti tetap dapat menjaga hubungan sosial dan membentuk ikatan antarpribadi dengan pemain lain sampai pada peningkatan hubungan sosial untuk mendapat teman baru dalam game sebagai akibat dari pemakaian virtual item tersebut.

3). Nilai dari emosionalnya

a. Estetika, mencerminkan fitur keindahan dari virtual item serta menarik untuk dilihat dalam segi desain dan perpaduan warnanya.

b. Kesenangan (playfulness), pemain menikmati jalannya sebuah permainan dan bersemangat untuk tetap memainkan game tersebut dengan membangkitkan imajinasi dalam bermain dan meresapi penggunaan virtual item dalam game tersebut.

\section{Pengembangan Hipotesis}

\section{Pengaruh Nilai Fungsional, Nilai Sosial dan Nilai Emosional Terhadap Intensi Pembelian Virtual Item PUBG Mobile.}

Menurut Tunjungsari \& Lunardy (2016) nilai fungsionaldalam menggunakan sebuah produk adalah value dari suatu produk berdasarkan pada suatu fungsi, kinerja fisik maupun kegunaan atribut dari sebuah produk . Monroe (1990) dalam (Tunjungsari \& Lunardy, 2016) 
nilai fungsional diartikan sebagai fungsui suatu produk yang didasarkan pada rasio atau pertukaran antara kualitas dan harga yang dipersepsikan oleh konsumen pada saat memperoleh produk tersebut. dalam bertransaksi pembelian untuk produk virtual, utilitas harga yang lebih besar akan menciptakan utilitas akuisisi dan kemauan yang lebih besar pula untuk membeli, dikarenakan konsumen percaya bahwa transaksi yang dilakukan tersebut lebih bernilai. Thaler (1985) dalam (Tunjungsari \& Lunardy, 2016).

Untuk kasus virtual item, Kim et al., (2009) dalam (Tunjungsari \& Lunardy, 2016) nilai sosial yang terdapat pada sebuah produk virtual dimaksudkan persepsi dari seorang konsumen akan sebuah nilai yang dapat meningkatkan citra dirinya pada lingkungan sosialnya, maupun hubungan sosialnya dengan orang lain yang berada di sekitarnya. Produk virtual dapat membantu meningkatkan representasi dan artikulasi seseorang di dunia virtual/online, sehingga seseorang dapat membeli dan menggunakan produk virtual untuk produk simbolis agar dapat menguatkan citra diri sosialnya, Kim et al. (2009) dalam (Tunjungsari \& Lunardy, 2016).

Nilai emosional dapat mempengaruhi pengambilan keputusan konsumen lewat potensi yang dimiliki untuk menimbulkan emosi konsumen sesaat setelah menggunakan suatu produk tertentu, Sweeney dan Soutar (2001) dalam (Tunjungsari \& Lunardy, 2016). Kim et al. (2009) dalam (Tunjungsari \& Lunardy, 2016) memiliki pendapat bahwasanya estetika dan kesenangan (playfulness) diyakini telah membentuk nilai emosional pada produk virtual. Kim et al. (2009) dalam (Tunjungsari \& Lunardy, 2016) berpendapat estetika dan kesenangan (playfulness) diyakini telah membentuk nilai emosional pada produk virtual. Daya tarik visual produk virtual yang diwakilkan oleh estetika dapat mendorong pembelian hedonistik, Rintamaki et al. (2006) dalam (Tunjungsari \& Lunardy, 2016). Kesenangan (playfulness) yang diperoleh dengan memiliki item produk virtual ternyata dapat memunculkan intensi pembeli tersebut dalam membeli sebuah produk, Kim et al. (2009) dalam (Tunjungsari \& Lunardy, 2016).

Berdasarkan uraian di atas, maka dapat diturunkan hipotesis dan kerangka konseptual dari penelitian ini sebagai berikut:

$\boldsymbol{H}_{1}$ : Diduga Nilai Fungsional berpengaruh terhadap Intensi Pembelian Virtual Item PUBG Mobile.

$\boldsymbol{H}_{2}$ : Diduga Nilai Sosial berpengaruh terhadap Intensi Pembelian Virtual Item PUBG Mobile.

H3: Diduga Nilai Emosional berpengaruh terhadap Intensi Pembelian Virtual Item PUBG Mobile.

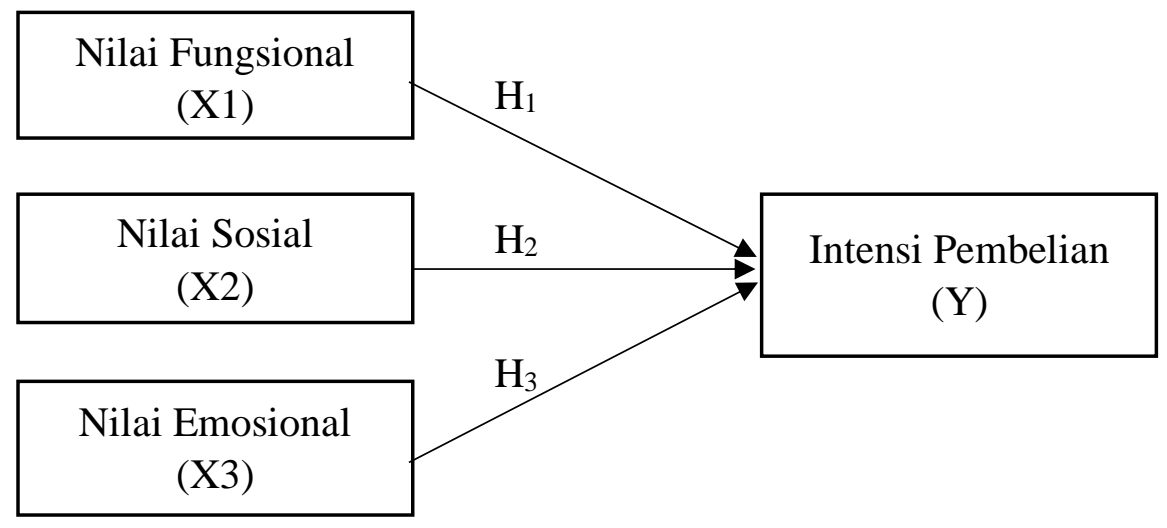

Gambar 1. Kerangka Konseptual

Sumber : Diadaptasi dari Ho \& Wu, 2012, Yoo, 2015, Tunjungsari \& Lunardy, 2016, Kim, Gupta, \& Koh, 2011, Miladian \& Sarvestani, 2012 


\section{Metode Penelitian}

Jenis penelitian ini menggunakan penelitian kuantitatif dengan populasi masyarakat Kota Banjarmasin yang pernah bertransaksi dan memainkan game PUBG secara online (PUBG Mobile) di Banjarmasin. Sampel penelitian ini dicari dengan menggunakan teknik nonprobability sampling memakai jenis teknik Judgemental Sampling. Kriteria sampel yang telah ditetapkan pada penelitian ini ialah 1) minimal berusia 17 tahun 2) telah memainkan game online PUBG Mobile selama kurang lebih 3 (tiga) bulan 3) Mengetahui manfaat nilai virtual item dalam game online PUBG Mobile.

Teknik analisis yang digunakan adalah analisis regresi linier berganda dengan SPSS versi 25. Menurut Ferdinand (2014) ukuran sampel yang lebih besar dari 30 dan kurang dari 500 sudah cukup untuk sebagian besar penelitian, besaran sampel yang ditentukan sebanyak 25 kali variabel independen. Dalam penelitian ini memiliki 3 variabel independen, 25 x $3=75$. Kemudian responden yang diambil digenapkan menjadi sebanyak 100 orang.

\section{Definisi Operasional Variabel}

Variabel-variabel yang digunakan dalam pengamatan ini didefinisikan pada Tabel 1, berikut ini:

Tabel 1. Definisi Operasional Variabel

\begin{tabular}{|c|c|c|}
\hline Variabel & Indikator & Sumber \\
\hline \multirow{3}{*}{$\begin{array}{l}\text { Nilai Fungsional (X1) : nilai yang terbentuk dari } \\
\text { kualitas atau kegunaan virtual item dimana jika } \\
\text { semakin berguna suatu virtual item sesuai situasi } \\
\text { dan keadaan dalam game tersebut maka semakin } \\
\text { tinggi pula intensi pembelian virtual item. }\end{array}$} & Kompetensi karakter & \multirow{3}{*}{$\begin{array}{l}\text { Ho \& } \\
\text { Wu } \\
(2012)\end{array}$} \\
\hline & Utilitas harga & \\
\hline & Kualitas fungsi & \\
\hline \multirow{2}{*}{$\begin{array}{l}\text { Nilai Sosial (X2) : Sebuah nilai yang dirasakan } \\
\text { oleh seorang individu yang bisa meningkatkan } \\
\text { citra diri dan sekaligus membangun hubungan } \\
\text { secara sosial antar para pemain game. }\end{array}$} & Ekspresi Citra Diri Sosial & \multirow{2}{*}{$\begin{array}{l}\text { Ho \& Wu } \\
(2012)\end{array}$} \\
\hline & Dukungan Hubungan Sosial & \\
\hline \multirow{2}{*}{$\begin{array}{l}\text { Nilai Emosional (X3) : nilai yang terbentuk dari } \\
\text { kemampuan virtual item dalam menimbulkan } \\
\text { dan mempertahankan rasa senang (playfulness) } \\
\text { dalam bermain game yang didapat dari } \\
\text { kepemilikan suatu virtual item. }\end{array}$} & Estetika & \multirow{2}{*}{$\begin{array}{l}\text { Ho \& Wu } \\
(2012)\end{array}$} \\
\hline & Kesenangan (playfulness) & \\
\hline \multirow{3}{*}{$\begin{array}{l}\text { Intensi Pembelian (Y) : keinginan atau disebut } \\
\text { niat yang muncul dari seorang pemain game } \\
\text { online untuk memiliki (pembelian) item yang } \\
\text { khusus digunakan pada game online itu sendiri } \\
\text { atau kerap disebut virtual item. }\end{array}$} & Pertimbangan & \multirow{3}{*}{$\begin{array}{l}\text { Ho \& Wu } \\
(2012)\end{array}$} \\
\hline & Kerelaan & \\
\hline & Kemungkinan & \\
\hline
\end{tabular}

\section{Hasil dan Pembahasan}

Responden yang dipilih merupakan masyarakat kota Banjarmasin yang pernah bertransaksi dan memainkan game PUBG secara online di kota Banjarmasin sebanyak 100 sampel. Pembagian kuesioner dilakukan secara online. Ditunjukkan karakteristik responden berjenis kelamin Pria sebanyak 85 orang dan responden berjenis kelamin Wanita sebanyak 15 orang. Mayoritas berusia 21-25 tahun yang berstatus sebagai mahasiswa. 


\section{Uji Validitas Dan Reliabilitas}

Pengujian menggunakan pearson correlation dengan SPSS versi 25. Suatu instrument dikatakan valid jika nilai $r$ hitung $>r$ tabel pada taraf signifikasi 5\%. Nilai $r$ tabel diperoleh dari degree of freedom $(\mathrm{df})=\mathrm{N}$ atau $(\mathrm{df})=100$ pada taraf signifikansi 5\% adalah 0,1946. Berdasarkan syarat signifikansi dari hasil perhitungan di atas didapatkan bahwa item dari masing-masing variabel dalam permodelan dinyatakan valid. Pada uji reliabilitas, hasil Cronbach Alpha dari semua variabel penelitian yaitu nilai fungsional, kemudian nilai sosial dan emosional serta intensi untuk membeli (intensipembelian) memiliki nilai diatas 0.70 sehingga dapat dikatakan kuesioner yang digunakan dapat dipercaya atau reliabel.

\section{Uji Normalitas}

Menurut Ghozali (2018) Uji normalitas memiliki tujuan untuk menguji apakah variabel pengganggu atau variabel residual di dalam model regresi yang digunakan memiliki distribusi normal. Seperti yang telah diketahui, uji $\mathrm{F}$ dan uji t mengasumsikan bahwa nilai residual mengikuti distribusi normal. Jika nilai sig. uji Kolmogorov-Smirnov bernilai di atas 0,05 maka data terdistribusi normal. Didapatkan hasil dari uji normalitas bahwa nilai signifikansinya dalam penelitian adalah 0,200 lebih besar dari 0,05. Hal ini menunjukkan bahwa sampel terdistribusi normal sehingga menunjukkan syarat model regresi sudah memenuhi syarat normalitas.

\section{Uji Multikolonieritas}

Menurut Ghozali (2018) uji multokoloneritas bertujuan untuk menguji apakah model regresi ditemukan adanya korelasi antar variabel bebas (independen). Pengujian multikolonieritas dengan melihat nilai Tolerence dan VIF. Data dikatakan bebas dari multikolonieritas jika nilai Tolerance di atas 0,10 dan nilai VIF di bawah 10. Berdasarkan hasil uji, diketahui bahwa nilai tolerance di atas 0,10 dan nilai VIF di bawah 10 , sehingga hasil ini menunjukkan tidak terjadi multikolonieritas dalam penelitian ini.

\section{Uji Heteroskedastisitas}

Menurut Ghozali (2018) uji heteroskedastisitas bertujuan menguji apakah dalam model regresi terjadi ketidaksamaan variance dari residual satu pengamatan ke pengamatan yang lain. Apabila probabilitas signifikansinya di atas 5\%, maka dapat disimpulkan model regresi tidak mengandung adanya heteroskedastisitas. Berdasarkan hasil uji, diketahui bahwa nilai probabilitas signifikansinya lebih besar dari 0,05. Hal ini menunjukkan bahwa tidak terjadi heteroskedastisitas pada model regresi.

\section{Uji Linieritas}

Menurut Ghozali (2018) uji ini digunakan untuk melihat apakah spesifikasi model yang digunakan sudah benar atau tidak. Variable dikatakan linier apabila nilai signifikansi kurang dari 0,05 .

Berdasarkan hasil uji, diketahui bahwa nilai pada nilai fungsional, nilai sosial dan nilai emosional kurang dari 0,05 maka dengan ini asumsi linieritas sudah terpenuhi

\section{Uji Model}

Untuk Uji statistik F, merupakan uji pengaruh bersama-sama (joint) digunakan untuk mengetahui apakah variabel independen secara bersama-sama atau joint mempengaruhi variabel dependen. Jika sig. $<(0,05)$ dan nilai $\mathrm{F}$ hitung $>\mathrm{F}$ tabel maka model regresi dapat digunakan untuk memprediksi variabel dependen. Berdasarkan perhitungan yang telah 
dilakukan terlihat bahwa nilai $\mathrm{F}$ hitung $>\mathrm{F}$ tabel dapat disimpulkan bahwa model dalam penelitian ini layak digunakan untuk menjelaskan pengaruh antara $\mathrm{X}$ dan $\mathrm{Y}$.

Uji model juga dapat dilihat dari nilai koefisien determinasinya, menurut Ghozali (2018) koefisien determinasi $\left(\mathrm{R}^{2}\right)$ pada intinya mngukur seberapa jauh kemampuan model dalam menerangkan variasi variabel independen. Nilai koefisien determinasi adalah antara nol dan satu. Nilai $\mathrm{R}^{2}$ yang kecil berarti kemampuan variabel-variabel independen dalam menjelaskan variasi variabel dependen amat terbatas. Nilai yang mendekati satu berarti variabel-variabel independen memberikan hampir semua informasi yang dibutuhkan untuk memprediksi variasi variabel dependen. Hasil perhitungan yang telah dilakukan menunjukkan besarnya nilai Adjusted $R$ Square adalah 0,391 atau 39,1\%. Nilai tersebut bermakna variabel intensi pembelian virtual item PUBG Mobile yang dapat dijelaskan oleh variabel nilai fungional, nilai sosial dan nilai emosional 0,391 atau 39,1\% sedangkan sisanya sebesar 0,609 atau $60,9 \%(1-0,391)$ dijelaskan oleh faktor - faktor lain yang tidak disertakan dalam model penelitian ini seperti variabel kepuasan bermain dan identifikasi bermain dalam model penelitian Ho \& Wu (2012) serta nilai uang dalam model penelitian Yoo (2015).

Nilai Adjusted $R$ Square sebesar 0,391 berarti intensi pembelian, nilai fungsional, nilai sosial dan nilai emosional dalam menjelaskan variabel intensi pembelian virtual item PUBG Mobile amat terbatas karena nilai 0,391 Adjusted $R$ Square jauh mendekati 1.

\section{Hasil Uji Hipotesis}

Hipotesis yang ada penelitian ini akan diuji dengan menggunakan uji t. Menurut Ghozali (2018) uji t (uji parsial) digunakan untuk mengetahui pengaruh masing-masing variabel independen terhadap variabel dependen. Jika sig. < 0,05, maka hipotesis $(\mathrm{H} 1, \mathrm{H} 2, \mathrm{H} 3)$ diterima atau variabel independen mempunyai pengaruh secara parsial terhadap variabel dependen.

Tabel 2. Hasil Uji t (Parsial)

\begin{tabular}{|c|c|c|c|c|c|}
\hline No & Hipotesis & $\mathbf{t}_{\text {hitung }}$ & $\mathbf{t}_{\text {tabel }}$ & Sig & Kesimpulan \\
\hline 1 & $\begin{array}{c}\text { Nilai Fungsional } \\
\text { berpengaruh terhadap } \\
\text { Intensi Pembelian Virtual } \\
\text { Item PUBG Mobile }\end{array}$ & 5,137 & 1,985 & 0,000 & $\begin{array}{c}\text { Hipotesis } \\
\text { diterima }\end{array}$ \\
\hline 2 & $\begin{array}{c}\text { Nilai Sosial berpengaruh } \\
\text { terhadap Intensi } \\
\text { Pembelian Virtual Item } \\
\text { PUBG Mobile }\end{array}$ & 1,802 & 1,985 & 0,075 & $\begin{array}{c}\text { Hipotesis } \\
\text { ditolak }\end{array}$ \\
\hline $\begin{array}{c}\text { Nilai Emosional } \\
\text { berpengaruh terhadap } \\
\text { Intensi Pembelian Virtual } \\
\text { Item PUBG Mobile }\end{array}$ & 0,624 & 1,985 & 0,534 & $\begin{array}{c}\text { Hipotesis } \\
\text { ditolak }\end{array}$ \\
\hline
\end{tabular}

Sumber: Diolah Peneliti, (2020)

Dari pengujian hipotesis dengan Uji t, diperoleh hasil pembahasan sebagai berikut:

\section{Pengaruh Nilai Fungsional terhadap Intensi Pembelian Virtual Item PUBG Mobile}

Hasil pengujian yang didapat dari output regresi linier berganda membuktikan bahwa variabel nilai fungsional memiliki dampak pada intensi pembelian virtual item PUBG Mobile dengan nilai t 5,137, signifikansi 0,00 dan koefisien 0,334. Hasil penelitian ini sejalan dengan 
hasil penelitian Ho \& Wu (2012) yang menyatakan bahwa nilai fungsional berpengaruh positif terhadap intensi pembelian virtual item PUBG Mobile.

Fungsi dari virtual item PUBG Mobile memiliki utilitas harga yang bernilai jika dilihat dari kegunaannya sehingga intensi pembelian virtual item PUBG Mobile akan meningkat karena pemain semakin memepertimbangkan membeli virtual item tersebut dan bahkan rela mengeluarkan uang riil untuk membeli item yang sifatnya hanya virtual.

\section{Pengaruh Nilai Sosial terhadap Intensi Pembelian Virtual Item PUBG Mobile}

Hasil pengujian analisis regresi linier berganda menunjukkan bahwa variabel nilai sosial tidak berpengaruh terhadap intensi pembelian virtual item PUBG Mobile dengan nilai t 1,802, signifikansi 0,075 dan koefisien 0,145. Hasil penelitian ini sejalan dengan hasil penelitian Ho \& Wu (2012) bahwa nilai sosial tidak memiliki pengaruh terhadap intensi pembelian virtual item PUBG Mobile.

Pemain PUBG di Banjarmasin sendiri terlihat ada yang punya intensi tinggi untuk membeli namun banyak juga yang intensi pembeliannya tergolong tidak tinggi yang mungkin disebabkan bahwa pemain PUBG di Banjarmasin karekteristiknya masih kebanyakan remaja dan mahasiswa sehingga tidak bisa sembarangan mengeluarkan uang untuk membeli item virtual karena adanya keterbatasan keuangan untuk konsumsi, dan masih banyak yang bergantung pada orang tua sehingga intensi pembeliannya tidak begitu tinggi.

\section{Pengaruh Nilai Emosional terhadap Intensi Pembelian Virtual Item PUBG Mobile}

Hasil pengujian analisis regresi linier berganda menunjukkan bahwa variabel nilai sosial tidak berpengaruh terhadap intensi pembelian virtual item PUBG Mobile dengan nilai t 0,624 , signifikansi 0,534 dan koefisien 0,056. Hasil penelitian ini sejalan dengan hasil penelitian Ho \& Wu (2012) bahwa nilai emosional tidak memiliki pengaruh terhadap intensi pembelian virtual item PUBG Mobile.

Game PUBG Mobile tidak hanya untuk bersenang-senang saja namun bisa diartikan untuk berkompetisi membuktikan siapa yang memiliki skill yang lebih hebat untuk bertahan sampai akhir dan memenangkan permainan sehingga pemain tidak mempertimbangkan untuk mengeluarkan uang riil agar memiliki virtual item PUBG Mobile

\section{Implikasi Hasil Penelitian}

\section{a. Nilai Fungsional}

Thaler (1985) dalam (Tunjungsari \& Lunardy, 2016) dalam bertransaksi pembelian untuk produk virtual, utilitas harga yang lebih besar akan menciptakan utilitas akuisisi dan kemauan yang lebih besar pula untuk membeli, dikarenakan konsumen percaya bahwa transaksi yang dilakukan tersebut lebih bernilai. Oleh karena itu, semakin tinggi nilai emosional maka akan meningkatkan intensi pembelian. Hasil dalam penelitian ini menunjukkan nilai fungsional memiliki pengaruh terhadap meningkatnya intensi pembelian virtual item PUBG Mobile yang dimana responden lebih memperhatikan fungsional atau kegunaan dari virtual item itu sendiri seperti kostum yang dibuat sedemikian rupa dengan medan pertempuran agar bisa digunakan untuk berkamuflase. PUBG bisa menambahkan lagi item-item yang memiliki fungsi serupa untuk berkamuflase di medan pertempuran agar lebih banyak variasi yang bisa dibeli/digunakan oleh pemain sehingga akan meningkatkan intensi pembelian virtual item PUBG Mobile. 


\section{b. Nilai Sosial}

Kim et al. (2009) dalam (Tunjungsari \& Lunardy, 2016) nilai sosial yang terdapat pada sebuah produk virtual dimaksudkan persepsi dari seorang konsumen akan sebuah nilai yang dapat meningkatkan citra dirinya pada lingkungan sosialnya, maupun hubungan sosialnya dengan orang lain yang berada di sekitarnya.. Produk virtual (dalam hal ini yaitu item virtual) dapat membantu memberikan upgrade dari sisi representasi dan artikulasi seseorang di dunia virtual/online, berkaitan dengan hal tersebut maka seorang pemain game online dapat membeli dan menggunakan produk virtual untuk produk simbolis agar dapat menguatkan citra diri sosialnya. Oleh karena itu, semakin tinggi nilai sosial maka akan meningkatkan intensi pembelian. Namun dalam hasil penelitian ini menunjukkan nilai sosial tidak memiliki pengaruh terhadap intensi pembelian yang disebabkan responden tidak terlalu peduli dengan pendapat atau kesan orang lain mengenai tampilan karakter mereka yang mereka fokuskan adalah skill bermainnya, tidak hanya pendapat atau kesan tentang penampilan karakter mereka dari pemain lain. Diharapkan PUBG dapat menambahkan fitur baru seperti tanda like untuk kostum yang digunakan oleh pemain agar pemain tahu bahwa kostum atau virtual itemnya diperhatikan oleh pemain lain mungkin dengan begitu pemain akan merasa di notice oleh pemain lain pada saat menggunakan virtual item tertentu sehingga akan meningkatkan intensi pembelian virtual item PUBG Mobile, serta diharapkan dengan melihat ekspresi orang lain akan penampilan karakter mereka akan membuat pemain merasa bangga dan akhirnya berpengaruh pada intensi pembelian mereka.

\section{c. Nilai Emosional}

Kim et al. (2009) dalam (Tunjungsari \& Lunardy, 2016) berpendapat estetika dan kesenangan (playfulness) diyakini telah membentuk nilai emosional pada produk virtual. Daya tarik visual produk virtual yang diwakilkan oleh estetika dapat mendorong pembelian hedonistik, Rintamaki et al. (2006) dalam (Tunjungsari \& Lunardy, 2016). Kesenangan (playfulness) yang didapat pembeli dari kepemilikan suatu produk virtual yang dapat menimbulkan intensi untuk membeli produk tersebut, Kim et al. (2009) dalam (Tunjungsari \& Lunardy, 2016). Oleh karena itu, semakin tinggi nilai emosional maka akan meningkatkan intensi pembelian. Namun dalam hasil penelitian ini menunjukkan nilai emosional tidak memiliki pengaruh terhadap intensi pembelian yang disebabkan responden bermain tidak hanya sekedar bersenang-senang saja tetapi lebih mementingkan kompetisi antar pemain lain untuk mendapat kemenangan. PUBG diharapkan menambahkan lebih banyak lagi variasi untuk fitur exclusive emotes pada kostum tertentu agar pemain lebih tertarik lagi untuk membeli virtual item sebagai akibat dari banyaknya variasi exclusive emotes yang ditampilkan dalam satu kostum sehingga hal ini akan meningkatkan intensi pembelian terhadap virtual item PUBG Mobile.

\section{Kesimpulan}

Berdasarkan hasil temuan pada penelitian ini maka dapat disimpulkan bahwa dalam permainan PUBG para responden yang merupakan pemain PUBG memperhatikan kegunaan virtual item sebagai pertimbangan dalam membelinya, yang berarti nilai fungsional mampu meningkatkan intensi para pemain untuk membeli virtual item PUBG Mobile pada masyarakat Banjarmasin. Namun terdapat bukti pula bahwa nilai sosial tidak memiliki dampak munculnya intensi para pemain untuk membeli virtual item PUBG Mobile, fenomena ini ditunjukan dengan adanya beberapa respon dari responden yang tidak terlalu peduli dengan pendapat atau kesan orang lain mengenai tampilan karakter yang dimainkan, hal utama yang menjadi fokus adalah skill bermain. Penelitian ini juga menemukan bahwa nilai emosional tidak memiliki pengaruh 
terhadap intensi pembelian yang disebabkan responden bermain tidak hanya sekedar bersenang-senang saja tetapi lebih mementingkan kompetisi antar pemain lain untuk mendapat kemenangan. Berdasarkan temuan temuan penelitian inilah maka developer PUBG dapat menambahkan beberapa item baru yang memiliki fungsi unik serupa dengan fungsi kamuflase di medan pertempuran, dan menghadirkan lebih banyak variasi item item virtual yang bisa dibeli/digunakan oleh pemain sehingga akan meningkatkan intensi para pemain untuk membeli virtual item pada PUBG Mobile.

\section{Daftar Pustaka}

Abdi, H. (2019). 6 Jenis Game Online Seru dan Terpopuler yang Harus Diketahui. Diakses dari https://hot.liputan6.com/read/4053559/6-jenis-game-online-seru-dan-terpopuleryang-harus-diketahui pada tanggal 12 April 2020.

Aswan, D. T., \& Maharani, I. (2019). Sejarah Perkembangan PUBG, Ternyata Pria Ini Penciptanya, Terinspirasi Film Remaja Jepang. Diakses dari https://makassar.tribunnews.com /2019/03/10/tribunwiki-pubg-jadi-game-favoritbegini-sejarah-perkembangannya-terinspirasi -film- remaja-jepang?page=all pada tanggal 29 Mei 2020.

Cha, J. (2011). " Exploring The Internet As A Unique Shopping Channel To Sell Both Real And Virtual Items: A Comparison Of Factors Affecting Purchase Intention And Consumer Characteristics ". Journal of Electronic Commerce Research, Vol 12, No 2.

Chapple, C. (2019). PUBG Mobile Surges Past \$1.5 Billion in Gross Revenue. Diakses dari https://sensortower.com/blog/pubg-mobile-revenue-one-point-five-billion pada tanggal 10 April 2020.

Fairfield, J. A. (2005). " Virtual Property. Boston University Law Review ", Research Paper Number 3585 B.U. L. REV. 1047.

Ferdinand, A. (2014). Metode Penelitian Manajemen. Semarang : Badan Penerbit Universitas Diponegoro.

Frank, L., Salo, M., \& Toivakka, A. (2015). " Why Buy Virtual Helmets and Weapons ? " Association for Information Systems. AIS Electronic Library (AISeL), 105, 2015; Bled, Slovenia.

Games, R. (2020). The 50+ Most Popular Mobile Games 2020, Ranked - Ranker. Diakses dari https://www.ranker.com/list/most-popular-mobile-games-today/ranker-games pada tanggal 10 April 2020.

Gcube. (2018). Apa Sih Pubg Mobile Itu? Sekilas Mengenai Game Battle Royale Mobile Yang Sedang Viral. Diakses dari https://pubgmobile.gcube.id/apa-sih-pubg-mobile-itu/ pada tanggal 12 April 2020.

Ghozali, I. (2018). Aplikasi Analisis Multivariate Dengan Program IBM SPSS 25. Semarang: Badan Penerbit Universitas Diponegoro.

Hamari, J., \& Lehdonvirta, V. (2010). " Game design as marketing: How game mechanics create demand for virtual goods '". Int. Journal of Business Science and Applied Management, Volume 5, Issue 1.

Ho, A. (2014). " 'The value of being powerful or beautiful ingames -how game design affects the value of virtual items' ". The Computer Games Journal, 3(1).

Ho, C.-H., \& Wu, T.-Y. (2012). " Factors Affecting Intent To Purchase Virtual Goods In Online Games ". International Journal of Electronic Business Management, Vol. 10, No. 3, pp. 204-212. 
Kim, H.-W., Gupta, S., \& Koh, J. (2011). "Investigating The Intention to Purchase Digital Items in Social Networking Communities: A Customer Value Perspective". Information and Management, 228-234.

Lehdonvirta, V. (2009). "Virtual item sales as a revenue model: identifying attributes that drive purchase decisions". Electron Commer Res , 9: 97-113.

Miladian, H., \& Sarvestani, A. K. (2012). " A Customer Value Perspective Motivates People to Purchase Digital Items in Virtual Communities ". International Conference on Economics, Business and Marketing Management, IPEDR vol.29 .

Park, B.-W., \& Chang, K. L. (2011). "Exploring The Value of Purchasing Online Game Items". Computers in Human Behavior 27, 2178-2185.

Pratama, K. R., \& Pratomo, Y. (2020). Gamer Cenderung Habiskan Uang untuk Game Mobile Ketimbang Konsol. Diakses dari https://tekno.kompas.com/read/2020/01/20/15140097/ gamer-cenderung-habiskanuang-untuk-game-mobile-ketimbang-konsol pada tanggal 17 April 2020.

Solahuddin, \& Juju, U. (2019). Pengaruh Nilai Virtual Item Dan Bauran Promosi Terhadap Proses Keputusan Pembelian Virtual Item Dalam Game Online DOTA 2 (Survei Pada Cyberia Net Bandung). Diakses dari http://repository.unpas.ac.id/41218/ pada tanggal 12 April 2020.

Suryono, R. R., \& Subriadi, A. P. (2016). "Perilaku Pemain Game Online Terhadap Pembelian Virtual Item". Jurnal Sistem Informasi, Volume 5, Nomor 5, hlm 578-584.

Tunjungsari, H. K., \& Lunardy, D. (2016). " ' Pengaruh Persepsi Nilai Pada Intensi Pembelian Produk Virtual Yang Dimediasi Oleh Kepuasan ". Mix: Jurnal Ilmiah Manajemen, Volume VI, No. 2.

Yoo, J. M. (2015). " Perceived Value of Game Items and Purchase Intention ". Indian Journal of Science and Technology, $\mathrm{Vol} 8(19)$. 